\title{
Language Theories Donation through Materials Development A case study in Jordan
}

\author{
Ali Ata Alkhaldi \\ Academic Support Department, Abu Dhabi Polytechnic \\ PO box 111499, Abu Dhabi, United Arab Emirates \\ E-mail: ali.alkhaldi@adpoly.ac.ae
}

Received: 17-12-2013

doi:10.7575/aiac.ijalel.v.3n.3p.112
Accepted: 04-02-2014

Published: 01-05-2014

\begin{abstract}
Materials development assists the teachers to understand and apply language learning theories and achieve professional development (Tomlinson, 2001) which this research has shown. This research aims to find out to what extent theories match the actual practice of materials and to help 'theorists' reflect upon language theories which are implicitly or explicitly embedded in the materials. It also aims to reveal the teachers' and learners' contributions in determining the practical theories. The sample of this research was purposive, that is, it was selected for a specific purpose to collect qualitative data and cover as wide a range as possible. The researcher interviewed thirty Jordanian teachers and students using qualitative research methods. The findings revealed some key principles donated by the participants, for example, 1) the materials should provide the learners with a variety of useful samples of discourse to enable them to use the language communicatively and meaningfully; 2) the materials should encourage the teachers' and learners' creativity; 3) the materials should take into account the teachers' and learners' preferences; and 4) the materials should take into consideration the specific and sensitive cultural aspects. Insightful implications and recommendations were suggested for future research.
\end{abstract}

Keywords: Theories, Principles, Materials Development, Evaluation, Professional Development

\section{Introduction}

The most effective way in the field of applied linguistics is materials development since theories can be made meaningful and relevant by reference to practical procedures which are at the heart of the process of teaching and learning (Tomlinson, 2003a). He maintains that materials development can help applied linguists and/or 'theorists' to articulate and develop their own language learning theories and to develop the necessary skills to put their theories into practice. Materials development studies can effectively provide applied linguists with effective practical evidence and help them to determine the effectiveness and validity of language theories which are embedded in the language materials.

Materials development is a dynamic and ongoing process which can effectively be carried out by teachers, learners and/or materials writers (Graves, 1996). Teachers, however, have underestimated how materials are developed and the developmental processes that are involved (Richards, 2001). Tomlinson (2001) indicates that materials development was treated as a sub-section of methodology, in which the introduced materials were presented as examples of methods in action. He maintains that a few books and articles dealt with features of materials development in the 1980s. Afterwards, courses started to give more prominence to materials development studies in the 1990s. Then, studies on materials development principles and procedures started to be published.

Tomlinson (2003a) argues that materials development is a field of study and a practical undertaking. As a field of study, it focuses on the principles and procedures of materials design, implementation and evaluation. As a practical undertaking, it contains the materials production, evaluation and adaptation. He argues that the two aspects are interactive in that the theoretical studies inform or are informed by materials development and used in the classroom. In other words, materials development is the process that can be conducted by applied linguists, materials writers, teachers and/or learners to provide useful data and principles that aims to develop language materials so as to achieve effective language learning.

The main potential objective of materials developers is to reduce the distance between research and classroom practice (Saraceni, 2003), but it seems that such an objective has not yet been achieved. Tomlinson and Masuhara (2004) argue that approaching the development of materials in principled, systematic and rigorous ways can help in making important discoveries about evaluated materials and help evaluators to learn a lot about materials, teaching and learning, and about themselves. Graves (2000) argues that "Decisions about developing materials are rooted in your beliefs, understandings and experience. ...Your experience has provided you with a basis for decision making as well as a repertoire of techniques." (p166). Such an experience can purposefully be utilised in providing valid theories and encouraging learners to master the second language. 


\subsection{SLA research and Materials Development}

The core argument is that there is a mismatch between the findings of research in second language teaching methodology and hypotheses and actual practice in many materials (Saraceni, 2003).

We do not yet possess a single overall theory of second language acquisition...no second language acquisition research can provide a definite answer to the real problems of second language teaching at this point... There is no pre-determined correct theory of language teaching originating from second language acquisition research. (Cook, 1996, pp.204-205)

Applied linguists and materials writers should not expect a definite answer from SLA research nor should they expect one research-based model of language learning to triumph over all the others (Tomlinson, 1998). However, this should not stop applied linguists from applying what they do know about the learning process of second language to the development of materials which are written to facilitate language learning (Tomlinson, 1998). He maintains that the knowledge of applied linguists about language learning is a result of thousands of years of reflective teaching and a century of experimental and observational research which can be used for formulating criteria that successfully contribute in developing language materials. The principles of this research are based on a body of research evidence to provide the field with valid and practical principles for developing English language materials effectively.

Despite the disagreements about the process of language teaching and learning (e.g., Ur, 1996 \& Timmis, 2004), there is a sufficient consensus on certain facilitating features of language learning to be useful in helping to articulate principles for evaluating and developing language materials (Tomlinson, 2003b). Language materials, therefore, should reflect useful and effective principles derived from SLA. The following SLA based principles have been applied to materials development:

- Materials should have an impact on learners in the sense that they provoke some emotion in the learners (e.g., Tomlinson, 2003b and Richards, 2001).

- Materials should involve relevant content to the target learners' needs (e.g., Cunningsworh, 1995).

- Materials should include relevant content to the target learners' interests (wants) which motivates learners to learn the target language effectively (e.g., Tomlinson, 2003b and Timmis, 2004).

- Materials should help learners feel secure and develop their confidence and independence (e.g., Crawford, 2002).

- Materials should develop the learners' awareness of the target language (e.g., Bolitho, 2003).

- Materials should develop learners' cultural awareness (e.g., McKay, 2002).

- Materials should assist learners to use the target language for communicative purposes (e.g., Mukundan, 2009).

- Materials should take into account different learning styles of learners (e.g., Oxford, 2001).

- Materials should reflect the learners' present and future uses (e.g., Cunningsworh, 1995).

- Materials should provide the learners with useful content that encourages them to be engaged in learning the language mentally and/or emotionally (Tomlinson, 2003b).

- Materials should be flexible in order to give the opportunity for teachers to adapt the materials to suit their learners' needs and interests (e.g., Crawford 2002 and Mukundan, 2009).

- Materials should provide teachers with methodological support to facilitate their job and provide inspiration to them to articulate creative teaching methods or ideas (e.g., Ur, 1996 and McGrath, 2002).

\subsection{Jordanian Educational Background}

English is taught as a foreign language at schools, whereas it is used as a medium of instruction in some faculties at the Jordanian universities such as the faculties of medicine, engineering, science, information technology, etc. Jordanian learners start learning English language from the beginning of their school life so they learn it from the first basic grade at the age of six or one year before until they finish their secondary learning. The same materials are used in all Jordanian schools. The current materials at Jordanian secondary schools are called Jordan Opportunities. The Ministry of Education in Jordan has adopted and adapted these materials to be taught since 2006. These materials were published by Longman in 2006 and they were written by Michael Harris, Anna Sikorzynska, David Mower and Michael Dean. The adaptation process was not completely clear, but a few texts were modified using some relevant Arabic pictures and names. For example, the name of the textbook was changed from New Opportunities into Jordan Opportunities.

\subsection{Rationale of the Research}

Teachers can be involved in the development of materials from the moment they use such resources and this means creating, selecting or adapting, and organising the materials (Graves, 2000). However, the teachers' input in donating language theories, principles for materials development, and evaluative criteria for local materials has not been researched thoroughly in the literature, particularly, in SLA research and local materials development literature. Furthermore, materials developers should make connections with the local environment to achieve successful materials development in which the materials writers attempt to help learners to understand first, to express their beliefs, attitudes, feelings, and convey what they want to say in their most realistic communicative situations (Dat, 2006). He maintains 
that theoretical support for designing materials within the local context is rare so this research will enrich the field with reliable and valid data and insights.

There are two significant factors which have motivated applied linguists to focus on materials development studies (Tomlinson, 2001). The first factor, the realisation that an effective method in helping teachers to understand and apply language learning theories and to achieve professional development is to provide monitored experience of the materials development process. The second factor, the appreciation that there is no ideal coursebook so effective teachers need to be capable of evaluating and developing materials to ensure a match between learners and their materials. It is true that there is no ideal or perfect coursebook (e.g., McDonough \& Shaw, 2003). As a result, the idea of 'no perfect/ideal coursebook' sheds light on the significance of developing practical principles for evaluating and developing the materials effectively.

\subsection{Related Case Studies in Jordan}

Studies were conducted in Jordan using different research instruments. Table 1 presents a summary of evaluation case studies conducted in Jordan.

Table 1. A Summary of Jordanian Case Studies

\begin{tabular}{|c|c|c|c|c|c|c|}
\hline $\begin{array}{l}\text { The } \\
\text { researcher }\end{array}$ & Year & $\begin{array}{l}\text { The book } \\
\text { evaluated }\end{array}$ & $\begin{array}{l}\text { Stage / } \\
\text { grade }\end{array}$ & $\begin{array}{l}\text { Instruments } \\
\text { used }\end{array}$ & Sample size & $\begin{array}{l}\text { The most salient } \\
\text { results }\end{array}$ \\
\hline Ababneh & 2007 & $\begin{array}{l}\text { Jordan } \\
\text { Opportunities }\end{array}$ & $\begin{array}{l}\text { Tenth } \\
\text { Grade }\end{array}$ & $\begin{array}{l}\text { Analysis } \\
\text { checklist, } \\
\text { questionnaires, } \\
\text { structured } \\
\text { interviews } \\
\text { (yes/no } \\
\text { questions) }\end{array}$ & $\begin{array}{l}\text { (80) teachers } \\
\text { and ( } 8) \\
\text { supervisors }\end{array}$ & $\begin{array}{l}\text { The teacher's book was } \\
\text { of great help to teachers. } \\
\text { There was a clear } \\
\text { agreement on the } \\
\text { suitability of "Jordan } \\
\text { Opportunities" from the } \\
\text { point of view of the } \\
\text { teachers and } \\
\text { supervisors. }\end{array}$ \\
\hline Shatnawi & 2005 & Cutting Edge & University & $\begin{array}{l}\text { Questionnaires } \\
\text { and analysis } \\
\text { checklist }\end{array}$ & $\begin{array}{l}\text { (300) } \\
\text { students and } \\
(20) \\
\text { instructors }\end{array}$ & $\begin{array}{l}\text { Two trends: The first } \\
\text { trend supported the idea } \\
\text { of including Western } \\
\text { culture, while the second } \\
\text { trend indicates that there } \\
\text { is a need for minimizing } \\
\text { the Western load of } \\
\text { cultural information in } \\
\text { TEFL. }\end{array}$ \\
\hline Alomari & 2002 & Action Pack & $\begin{array}{l}\text { Primary } \\
\text { stage }\end{array}$ & $\begin{array}{l}\text { Questionnaires } \\
\text { and highly } \\
\text { structured } \\
\text { observations }\end{array}$ & $\begin{array}{l}10 \\
\text { supervisors } \\
\text { and (275) } \\
\text { teachers }\end{array}$ & $\begin{array}{l}\text { The results of the study } \\
\text { revealed that the } \\
\text { respondents agree on the } \\
\text { suitability of Action } \\
\text { Pack textbooks. }\end{array}$ \\
\hline Almomani & 1998 & $\begin{array}{l}\text { AMRA } \\
\text { (Advanced and } \\
\text { More Relevant } \\
\text { Activities) }\end{array}$ & $\begin{array}{l}\text { Secondary } \\
\text { Stage }\end{array}$ & $\begin{array}{l}\text { Questionnaires, } \\
\text { structured } \\
\text { interviews and } \\
\text { structured } \\
\text { observations }\end{array}$ & $\begin{array}{l}(1400) \\
\text { students, } \\
(240) \\
\text { teachers and } \\
(30) \\
\text { supervisors }\end{array}$ & $\begin{array}{l}\text { The objectives met the } \\
\text { learners' needs and the } \\
\text { vocabulary items were } \\
\text { selected to suit the } \\
\text { students' level. The } \\
\text { textbooks were good in } \\
\text { terms of their general } \\
\text { aspects. However, the } \\
\text { topics were not to be } \\
\text { found interesting and } \\
\text { listening and speaking } \\
\text { skills were not } \\
\text { emphasised. }\end{array}$ \\
\hline Al-Kofeiri & 1997 & $\begin{array}{l}\text { PETRA } \\
\text { (Progress in } \\
\text { English } \\
\text { Through } \\
\text { Relevant } \\
\text { Activities) }\end{array}$ & Tenth grade & A questionnaire & $\begin{array}{l}(120) \\
\text { teachers }\end{array}$ & $\begin{array}{l}\text { The teachers' views } \\
\text { about the textbooks } \\
\text { were positive. However, } \\
\text { the participation of } \\
\text { teachers in selecting the } \\
\text { objectives was not } \\
\text { adequate. }\end{array}$ \\
\hline
\end{tabular}




\begin{tabular}{|l|l|l|l|l|l|l|}
\hline Al-Salah & 1992 & $\begin{array}{l}\text { Teachers' } \\
\text { guides of the } \\
\text { revised Oxford } \\
\text { English course }\end{array}$ & $\begin{array}{l}\text { Secondary } \\
\text { stage }\end{array}$ & A questionnaire & $\begin{array}{l}\text { (162) } \\
\text { teachers }\end{array}$ & $\begin{array}{l}\text { Teachers' guides were } \\
\text { of no significant help to } \\
\text { teachers in the process } \\
\text { of teaching. }\end{array}$ \\
\hline Saleh & 1990 & PETRA (four) & $\begin{array}{l}\text { Second } \\
\text { preparatory }\end{array}$ & Questionnaires & $\begin{array}{l}\text { (45) } \\
\text { teachers, } 10 \\
\text { trainers and } \\
3 \\
\text { supervisors } \\
\text { objectives of the } \\
\text { textbook were suitable } \\
\text { and clear for teachers } \\
\text { and pupils. But the } \\
\text { introduction of PETRA } \\
\text { textbooks was not found } \\
\text { to be clear enough. }\end{array}$ \\
\hline El-Mostafa & 1988 & PETRA (three) & $\begin{array}{l}\text { First } \\
\text { preparatory }\end{array}$ & $\begin{array}{l}\text { Questionnaires } \\
\text { she textbook was } \\
\text { adequate. However, the } \\
\text { instructions of the } \\
\text { evaluated textbooks } \\
\text { were not clear. }\end{array}$ \\
\hline Al-Jarrah & 1987 & $\begin{array}{l}\text { PETRA (one } \\
\text { and two) }\end{array}$ & $\begin{array}{l}\text { Fifth and } \\
\text { Sixth } \\
\text { Elementary }\end{array}$ & $\begin{array}{l}\text { Questionnaires } \\
\text { and (666) } \\
\text { pupils }\end{array}$ & $\begin{array}{l}\text { (29) teachers } \\
\text { supervisors, } \\
\text { graduate } \\
\text { students and } \\
\text { professors, } \\
\text { and (80) } \\
\text { teachers }\end{array}$ & $\begin{array}{l}\text { PETRA textbooks were } \\
\text { good, but they did not } \\
\text { have clear introductions } \\
\text { and instructions. }\end{array}$ \\
\hline
\end{tabular}

The analysed data in the table shows that Jordanian researchers from 1987 to 1997 only relied upon questionnaires to evaluate the materials, in particular, the materials of the basic stage. Afterwards, they started to use other instruments for evaluation. A few Jordanian researchers used interviews and/or observations, in particular, highly structured interviews and/or observations. However, they might not have researched the addressed issues well as discussed below. The most noticeable change might be the use of Likert scale; it has been changed from three Point Likert scale (e.g., in 1990) into Five Point Likert scale (e.g., in 2002). Most studies focused on the opinions and attitudes of teachers and supervisors, that is, few studies had the learners' perceptions.

With regard to evaluation criteria, most evaluative items were not clear. They, for example, had more than one item to ask in one question/item. In Ababneh's (2007) study, for example, he used the following items: "Relevance of listening and speaking activities to students' background" and "Appropriateness of the writing activities to the learners' needs and age". He asked about two things at the same time and this might have confused respondents. Furthermore, the items were vague and/or long such as the following item "Listening and speaking activities teach how to combine functional units of language to create discourse and how to recognize the structure of discourse" (Almomani, 1998 and Alomari, 2002). Moreover, it seems that there was no clear approach or system showing how the instruments and/or criteria were developed or adapted.

It is also clear that the Jordanian researchers could not have distinguished between evaluation and analysis. In other words, they mixed between evaluation and analysis. For example, the following items (among others) were asked as evaluation items in the questionnaires and/or interviews despite the fact they are related to analysis: "providing prereading, while-reading and after reading activities", "Providing word list", and "Provision of class cassettes and students' CD". Unfortunately, it seems that there were no clear frameworks and principles for materials evaluation and development in Jordanian case studies. This may show that there is really "a research gap" between the Jordanian research context and SLA research, materials evaluation research, and research methodology. The reviewed literature of materials evaluation in Jordan reveals that there is a need for identifying practical principles and criteria based on SLA research which this research has done.

With regard to the findings of the Jordanian case studies, they revealed that PETRA textbooks did not have clear introductions and instructions (e.g., Al-Jarrah, 1987 and Saleh, 1990). The teachers' guides of the secondary stage were not helpful to the Jordanian teachers (Al-Salah, 1992). Furthermore, the objectives of AMRA textbooks met the learners' needs and they were good in terms of their general aspects, however, the topics were found not to be interesting (Almomani, 1998). Moreover, Action Pack textbooks (Alomari, 2002) and Jordan Opportunities (Ababneh, 2007) were suitable to the learners' needs from the point of view of teachers and their supervisors. It seems that the findings might not have provided deep insights and guidelines for future research and professional development training. The reasons may lie in the fact that principles for materials development and/or principled criteria for materials evaluation were not effectively developed, and the process of materials evaluation and development was not appropriately elaborated. In other words, the findings and recommendations were based on vague criteria without taking into consideration the principles and insights for future materials development research, applied linguistics training, and professional development. Consequently, there is "a research gap" between the Jordanian research context and SLA 
research, and materials development research (see 1.1 SLA research and materials development and 1.3 rationale of the research).

\section{Methodology}

The qualitative research is used in this research for the following key characteristics among others:

- Natural setting: The researcher collected data in the field at the site where participants experience the issue under study (Creswell, 2009).

- $\quad$ Researcher as key instrument (Creswell, 2009): The researcher of this study is an insider, that is, his position as a researcher is necessary for the research to see the meaning from the inside.

The researcher's perceptions of English language education have been shaped by his personal experiences. He learned English language in Jordanian schools from grade five until grade twelve. Then he earned his master's degree in English language. Afterwards, he worked as a teacher of English. He believes that his understanding of the situation and his positive role enhances his awareness, knowledge and sensitivity to many of the challenges and issues encountered in his research. In addition, this has helped him in working with the participants of this study effectively and positively and in building a good relationship with the participants during the data collection process. As a result, his attitudes may positively influence his approach to the research. However, the researcher acknowledges the possibility that there may also be a negative side, that is, he may have certain prejudgments, consciously or subconsciously.

- Inductive data analysis: this process illustrates working back and forth between the themes and the database until the researcher has established a comprehensive set of themes. Although the reasoning is largely inductive, the processes of deductive and inductive are both at work (Creswell, 2009).

- Insider meaning of the participants: Qualitative research is concerned with subjective opinions, experience and feelings of individuals and thus the explicit purpose of research is to explore the participants' views of the situation being viewed (Dörnyei, 2007).

\subsection{Participants}

The researcher selected 30 participants from the Jordanian Ministry of Education: 10 male and female teachers, 10 male and female learners from grade eleven, and 10 male and female learners from grade twelve. The researcher selected the sample purposefully, that is, it has been selected for a specific purpose (Cohen, Minion, \& Morrison, 2007) to collect qualitative data (e.g., Dörnyei, 2007) and cover as wide a range as possible. The interviewees voluntarily accepted to be interviewed to talk about their opinions and experience of using the Jordanian materials for teaching and learning English language.

All the teachers are holders of Bachelors or Masters degrees in English language and they have various years of experience in teaching English language. The learners started learning English language from the beginning of their school life (see 1.2 Jordanian Educational Background). Furthermore, there are two main stages of education in Jordan; the first stage is the basic stage which consists of the first ten basic grades. Learning is compulsory in this stage, that is, learners must finish learning all the first ten basic grades to be able to further their learning in the secondary stage or leave schools for one reason or another. The second stage is the secondary stage which consists of two secondary grades: eleventh and twelfth It is optional for learners whether they wish to further their secondary learning and study at universities after this stage or not.

\subsection{Research Instrument}

The researcher developed two interview guides of semi-structured interviews; one for teachers and the other for the learners. The format is open ended and the interviewee is encouraged to elaborate on issues raised in the explanatory manner (Dörnyei, 2007). In other words, the format involves open-ended questions which encourage participants to speak therefore obtaining in depth data. The researcher developed the interview guides after a thorough reading of the relevant literature (e.g., see Alkhaldi, 2011).

The teachers' interview schedule included seven questions; the questions reflected the purpose of the study (Cohen, Manion \& Morrison, 2007). They were about the suitability and effectiveness of the materials and their objectives to the learners' needs, the changes that participants would like to see in the materials, the reading texts (activities) that they like or dislike, the usefulness and effectiveness of the teacher's book, the positive as well as the negative characteristics of the materials, and their suggestions to improve the materials. There was also a section at the end of the interview schedule for any other comments. The purpose of this section was to get in-depth data and increase the flexibility of the interviews by giving the participants more freedom to address any other comments, ideas and/or suggestions (See Appendix A).

The other interview schedule was for obtaining the learners' views about the target materials that they used for learning English language. The interview schedule contained six questions; they were about the most and least useful activities in the materials, the reading texts (activities) that they like and/or dislike, the strong and weak points in the materials and their suggestions to improve the materials. There was also a section at the end of the interview schedule to address other comments, ideas and/or suggestions (See Appendix B). 


\subsection{The Evaluated Materials}

This research evaluated Jordan Opportunities materials i.e. Students' books, Workbooks, Teachers' books which were used for grades eleven and twelve. These materials were adapted and used by the Ministry of Education in Jordan for the secondary stage. The materials for grade eleven were first prescribed by the Jordanian Ministry of Education in the academic year 2006/2007 and were prescribed for grade twelve in 2007/2008. Based on the researcher's best knowledge, the Jordan Opportunities materials of grade ten were evaluated by a Jordanian researcher; however, the materials of this research were not evaluated and developed before conducting this research. The key issue is not only the materials themselves, but it is also the professional development, applied linguistics training, and insights that can be gained through principled and rigorous materials evaluation and development which this research did. (See 1.3 the rationale of the research and 1.4 related case studies in Jordan).

\subsection{Procedures}

The following procedures were followed to carry out this research:

\subsubsection{Data Collection}

The researcher conducted face to face interviews. He interviewed learners and teachers in different schools and areas. The researcher made every effort to make sure that the participants felt comfortable in the interviews before recording them on a digital tool. The learners were interviewed in Arabic language, whereas the teachers were interviewed in English language, except two teachers who preferred to be interviewed in Arabic language.

\subsubsection{Data Analysis}

The participants' responses were analysed and the emerging themes were classified in categories. The researcher looked at the analysis of the qualitative data as the following steps from the specific to the general and as involving the following multiple levels of analysis (Creswell, 2009):

Step 1: Organise and prepare the data for analysis.

Step 2: Read through all the data.

Step 3: Begin detailed analysis with an inductive coding process; from specific to general.

Step 4: Use the coding process to generate a description of the setting or people as well as categories or themes for analysis.

Step 5: Advance how the description and themes will be represented in the qualitative narrative.

Step 6: A final step in data analysis involves making an interpretation or meaning of the data.

The researcher organised and prepared the data for analysis, that is, he transcribed the interviews. He read through all the data and obtained a general sense of the information gained. Afterwards, he began a detailed analysis, that is, he moved back and forth between data analysis and interpretation relying on the pre-determined issues and the emergent results. In other words, after transcribing the recorded files, the researcher started reading and re-reading the transcripts several times and coding. During and after the coding process, the researcher categorised the codes and made notes of the ideas that came to his mind (memos).

\section{Findings and Discussion}

The findings revealed some themes, principles, and criteria for evaluating and developing language materials which possibly reduce the distance between research and actual use of the materials.

\section{The Materials and their Objectives Correspond with the Learners' Needs}

Most of the teachers answered "Yes" and they ascribed the reasons for such a correspondence to a variety of reasons. The majority of them considered the main reason was vocabulary, grammar, and reading texts included in the materials. Two interviewees were in disagreement; RW said it was suitable for "our culture", but ZA disagreed with RW. It seems that both RW and ZA have different definitions or attitudes towards 'our culture' since RW justified her response with different topics which were included in the materials, whereas ZA justified her response with narrow objectives which were not linked to the Jordanian market saying:

"I think they do not correspond to our learners' needs because the objectives are very narrow and erer the context does not match our culture ... And also the objectives are not linked to our market."

This is an interesting point that links the needs of the learners with the needs of the Jordanian market (business) for future purposes. This point leads to another important point that the teachers might not have known the general (national) goals of the secondary grades and the aims of the Jordanian Ministry of Education for this stage. RN, for example, commented:

"We must know all as teachers what are the objectives of our curriculum? What are the objectives of ours
syllabi?... I know the objectives, the goals, the aims of each lesson ... the objectives where, where I can, can I
find the description of the objectives?... I have objectives for myself..."

$\mathrm{RN}$ expressed her unawareness of the aims indicating that she did know them. This might show some weaknesses or vagueness of the teaching and learning process.

AL said: 
"We have a general err objective here err in Jordan because we have a time of tourism ... our student's needs is to be accurate ... because the err general examination which is designed by the Ministry of Education concentrates on grammar ... to master the language in the feeling of accuracy rather than fluency. ... but there is a big gap between the err let us say the general objective of our country \{fluency\} in accordance with the time we live now our country lives now and they let us say the err objective of the Ministry of Education $\{$ accuracy\}."

This interesting piece of information could generate an evaluation criterion for national English specific needs. The criterion could be "To what extent do the materials prepare the learners for national English needs properly?" AL indicated that the aural and oral skills were overlooked in the exams and the main focus of the exam paper was grammar.

\section{There is Likely to be a Bias between Boys-Girls Interests/Relationship}

An interesting point about a possible bias in the materials was reported by a teacher since some topics focus on issues related to boys rather than girls. RW said:

"I think some of topics are more kind of boyish you know... (I mean) like cars, political issues, and umm footballers, heroes... (I mean) these things are more boyish (I mean)... not interesting topics for girls... as you know I teach girls you know... except unit of food and cooking things are interesting, but I feel that my students feel bored when we talk about some topics like heroes and men heroes... footballers."

This is an interesting point mentioned by RW who thinks that the materials had a bias for boys rather than a balance between both boys and girls. Such a significant point can be incorporated as a criterion in a locally sensitive evaluation framework.

Furthermore, another female teacher generated a similar idea without specifically realising such a potential bias; NA said about reading texts "Some of them are away from the students' interests". It is also useful to highlight that this might be due to the gap between the Jordanian and British culture upon which the materials have been based, that is, some topics (e.g., bikes, football) might be interesting for young adults in Britain (for both boys and girls), whereas they are culturally more interesting for Jordanian boys rather than Jordanian girls. Some commentators emphasise the importance of including the learners' culture and multicultural information without specifying the content with English speaking countries only (e.g., McKay, 2002). The young adults or teenagers of boys and girls in Britain study together in the classrooms having relatively similar interests, needs, or issues, whereas the boys and girls in Jordan are separated from each other and topics such as cycling or playing football and climbing mountains are culturally more restricted to boys rather than girls in Jordan. This reveals that the authors may not be aware of some specific cultural differences between the two cultures or the Jordanian Ministry of Education has not adapted the materials properly.

\section{The Teacher's Book is Pedagogically Effective and Informative}

All the teachers agreed that the teacher's book is pedagogically helpful. They reported that the teacher's book is very useful, effective and helpful in teaching the materials; therefore, it is considered as a methodological support for teachers whether they partially or fully depended on it in teaching their lessons.

Regarding the linguistic importance of the teacher's book, some teachers reported that the teacher's book helped them in developing their language skills; whereas others reported that it did not help them indicating that any written paper can be useful for language input.

IB said:

"Frankly speaking, not only the teacher's book, but also any book I read may be useful....Maybe, but I believe any other book you read whether it is the teacher's book or any other book may be useful for your language skills."

It is worth indicating that there was not a specific question about the role of the teacher's book in improving the language but it was asked as an example, among others, for the potential effectiveness and usefulness of the teacher's book. This could generate a new criterion; the criterion might be "Does the teacher's book help the Non-native teachers with language?"

Furthermore, a few teachers reported that they do not commit to the teacher's book giving their own reasons such as the teaching methods of the teacher's book may not be suitable for all classes, the reality may be different from what is written in the teacher's book, or it may restrict their creativity. AL, for example, said:

"We can't err we can't say that there is one method is suitable for everything. let us say this is err related to Eclectic method... because we have differences among our schools here in Jordan or let us say in the Middle East this is from one point of view, another point of view, we have individual differences inside the class so ... the teacher's book itself gives let us say one way or err criteria or such methods, but these methods can be used in one class, but can't be used in another class, why? Because we have differences...differences among our schools, ... individual differences among our students and we have teacher's differences."

A new point emerged from the responses of AL. He said that there are individual differences among students as well as teachers. Therefore, flexibility and options emerge as an option. This important point can be taken into account in developing criteria and principles for materials evaluation and development. 
The Teachers and Learners View Grammatical Structures and Vocabulary as the Main Elements for Learning a Foreign Language

The Jordanian teachers and learners view grammatical structures and vocabulary items as the main elements for learning a foreign language. Most teachers believe that grammar and its presentation is one of the main strong points of the materials. Furthermore, most learners believe that the most useful activities are grammar and vocabulary. The reasons according to their point of view are varied; some learners believe that grammar and vocabulary are the main elements in learning the language, since they help them to do the grammatical exercises and translate the meanings of the vocabulary from English into Arabic and vice versa.

Student 1, for example, (S1) said:

"Grammar, the explanation of grammar from the teacher, the meaning of the vocabulary items helps us to learn; translate the words."

The reason for this might be that the common techniques of teaching and learning in Jordan are based on how to teach and learn the language not for the sake of learning the language effectively but for the sake of passing the exams. In other words, learners and teachers focus on grammar and vocabulary as the main elements for learning English and passing the exams.

\section{The Teachers' Role and/or Preferences Might not have been Taken into Account by the Materials}

It seems that the materials have been designed to be taught in a way without taking the teachers' preferences into account. In other words, the materials were possibly designed to be taught in schools according to some specific way without any flexibility for the teachers' intervention or mediation, so their role might be limited or passive. AL said:

"We teach student depending on the material itself to train students to master the language accurately ...many activities inside the material that train students to be accurate rather than to be fluent..."

RN said:

"The teacher all the time spend all his time err talking in Arabic.... He uses the bilingual list to translate (I mean) he use the translation method ...Because our students (I mean) the most important thing is the grades, is the exams, especially the final exam.... We prepare our students just to pass the exam... to speak English to it is not important... we teach according grammar translation method."

The analysis provides insights about the teachers' own preferences. This is an interesting piece of information that generates insights for evaluating and developing materials. The donated criterion might be 'Do the materials take account of the teachers' methodological preferences?' That does not mean that they have to just follow the teachers' preferences, but that they are based on an understanding of teachers' preferences.

The Learners Have Different Preferences, but they are not Satisfied Entirely with the Content of the Materials

The students have their own preferences and they are not completely satisfied with the topics included in the materials. They expressed their opinions regarding what they like in the reading texts. For example, some students preferred the adventure reading texts and disliked fiction.

S2 preferred historical information (Jordanian/Arabian culture) saying:

"Omayyad is a useful and interesting reading text...Because it is a text that presents historical information... I think that I could express my opinions in two languages Arabic and English when I was asked about history in English language."

S2 provided an interesting insight about the value of including the culture of the target learners which might be overlooked in some materials. This might be useful to be included as a criterion for evaluating and developing materials. The criterion might be 'How far do the materials enable learners to discuss their own culture in L2?'

The results show that the students have different preferences and most of the topics are not from the common interests of the learners. Furthermore, the teachers were in disagreement whether the reading texts or language was difficult or easy since their learners might be at different levels and have different preferences; RW said "I like everything about reading texts ... also I like the arrangement of grammar". AM complained that the language of the materials was difficult and RW reported that language was suitable to the learners. The teachers viewed the presentation of grammar in the texts as interesting in a way that matched the levels of their learners. Such results provide insights about different preferences of learners and teachers.

To sum up, the findings provided practical criteria and principles for evaluating and developing language materials. The donated principled criteria are:

- The potential bias between boys/girls interests/relationship suggests locally sensitive evaluation instrument and relevant criteria to such relationships/interests can be articulated.

- The effect of the materials/teachers' books on raising the teachers' awareness of the objectives and aims of the materials, and how they facilitate creative language teaching. The criteria might be "To what extent does the teacher's book raise the teacher's awareness of the aims?" and "To what extent do the materials facilitate creative language teaching?" 
- The role of the teacher's book in assisting the non-native teachers with the language. The criterion might be "Does the teacher's book help the Non-native teachers with language?"

- The flexibility of the materials and options towards using a variety of techniques and methods for teaching and learning the language materials effectively. The potential criterion might be "To what extent do the materials provide a useful variety of options for teaching the materials?"

- Taking into account the teacher's methodological preferences by the materials themselves. The criterion might be "To what extent do the materials take account of the teachers' methodological preferences?"

- The role of the materials in preparing the learners for specific national needs such as tourism. The criterion could be "To what extent do the materials prepare the learners for national English needs properly?"

- The role of the materials in enabling the learners to discuss their own culture in L2. The criterion might be "How far do the materials enable learners to discuss their own culture in L2?"

\section{Conclusion}

The findings reveal that there is a mismatch between a few principles and the materials and/or practice such as giving the opportunity for teachers to adapt the materials, using the materials appropriately for communicative purposes, and helping the learners to develop their confidence and/or independence. Furthermore, the findings unveil the practical language theories and criteria donated by the teachers to bridge the gap between research and the actual use of materials. Therefore, evaluating language materials is very useful and effective in achieving effective materials development and the target users are a useful source for donating practical theories (Ivor Timmis: personal communication).

The findings also revealed that there is a need to develop a framework for developing the materials to put theories into practice. The following donated principles have been developed to represent valid and practical principles for materials development:

1. The materials should provide the learners with a variety of useful samples of discourse to enable them to use the language communicatively and meaningfully.

2. The materials should be flexible to help the teachers to have a role for adapting the materials. This might be achieved by providing them with more options in language items/samples and teaching methods.

3. The materials should encourage the teachers' and learners' creativity and provide the teachers with clear aims and objectives.

4. The materials should clearly state the overall methodology/approach that they adopt to enable the teachers to teach the language effectively. It might be better that they should not restrict the users with a limited option.

5. The materials should take into account the teachers' and learners' preferences. That does not mean they have to just follow the learners' and teachers' preferences, but that they are based on an understanding of learners' and teachers' preferences.

6. The materials should help the learners to have exposure to language skills and components appropriately. In other words, the focus should not be on one or two skills (e.g., reading) and one or two components (e.g., grammar, lexis) at the expense of other important skills (e.g., listening) and components (e.g., lexical chunks or phonology).

7. The materials should take into consideration the specific and sensitive cultural aspects to motivate learners to be engaged in language learning.

\subsection{Implications and Recommendations}

This study raised potential issues that affect the role of the materials, teaching and learning English in relation to a specific context in which English is used as a Foreign Language. It raised issues that can help in developing potential principles, research methods, and evaluative criteria in a thorough way. Teachers' understanding of how to utilise their experience and the theories of others raises important questions about the relationship between theory and practice (Graves, 1996). The development of the principles and criteria can contribute in filling the research gap between the principles and the materials. In other words, new insights emerged to bridge the gap between theory and practice.

Further research is suggested to achieve more insights about the process of evaluation, the evaluation and development frameworks, and the effectiveness of English materials. This might include using, for example, the suggested principles and criteria. It is also worth taking the washback effect into account, that is, there should be some investigation about exam systems, the coverage of exam items in relation to the activities of the materials and the students' achievements. Evaluating and developing such issues may reflect positively on developing English language education since exams are obligatory for all learners in many different parts of the world. However, focusing on exams might be self defeating, in particular, if the producers of materials are sacrificing materials aspects that are believed to facilitate the acquisition of SL/FL to satisfy market demands (Masuhara \& Tomlinson, 2008).

When this research is intended to be used by other researchers, the donated evaluation criteria need to be taken into consideration such as: a) the potential bias between boys/girls interests/relationship towards locally sensitive evaluation 
instruments, b) the effect of materials and training programmes on raising the teachers' awareness of the objectives and aims of the materials, and how the materials facilitate creative language teaching, c) the role of the teacher's book in assisting the non-native teachers with the language, d) the flexibility of the materials and options towards using a variety of techniques and methods for teaching and learning the materials effectively, e) taking into account the teachers' methodological preferences, f) taking into account the learners' learning preferences 'topics' seriously, g) the role of the materials in preparing the learners for specific national needs such as tourism, and h) the role of the materials in enabling the learners to discuss their own culture in L2.

\section{Acknowledgement}

I would like to express my deep thanks and appreciation to Prof. Ivor Timmis and Prof. Jayakaran Mukundan for their advice and inspiration.

\section{References}

Ababneh, J. (2007). Analyzing the content of "Jordan opportunities" series for the basic stage Jordanian students and investigating teachers' and supervisors' opinions. Unpublished doctoral dissertation, Amman Arab University for Graduate Studies, Amman, Jordan.

Al-Jarrah, Z. (1987). Analysis and evaluation of the new textbooks (PETRA) for the fifth and sixth elementary classes in Jordan. Unpublished master's thesis, Yarmouk University, Irbid, Jordan.

Alkhaldi, A. (2011). Materials Development in Jordan: An Applied Linguistics Challenge. Unpublished doctoral dissertation, Leeds Metropolitan University, Leeds, UK.

Al-Kofeiri, Q. (1997). An evaluation of the English textbook (PETRA) for the tenth grade in Jordan from teachers' perspectives. Unpublished master's thesis, Yarmouk University, Irbid, Jordan.

Almomani, N. (1998). An evaluation of EFL textbooks (AMRA) for the first and second secondary classes in Jordan: Students', teachers' and supervisors ' perspectives. Unpublished master's thesis, Yarmouk University, Irbid, Jordan.

Alomari, B. (2002). An evaluation of Action Pack: teachers' and supervisors' perspectives. Unpublished master's thesis, Yarmouk University, Irbid, Jordan.

Al Salah, M. (1992). An evaluation of English teacher's guide of the secondary cycle in Jordan. Unpublished master's thesis, Yarmouk University, Irbid, Jordan.

Bolitho, R. (2003). Materials for language awareness. In B. Tomlinson (Ed.), Materials Development for Language Teaching, (pp.422-425). London: Continuum Press.

Cohen, L., Manion, L. \& Morrison, K. (2007). Research Methods in Education (6th ed.). London: Routledge.

Cook, V. (1996). Second Language Learning and Second Language Teaching. London: Edward Arnold.

Crawford, J. (2002). The role of materials in the language classroom: Finding the balance. In J. Richards \& W. Renandya (Eds.), Methodology in Language Teaching: an Anthology of Current Practice, (pp.80-90). Cambridge: Cambridge University Press.

Creswell, J. (2009). Research Design: Qualitative, Quantitative, and Mixed Methods Approaches (3rd ed.). Thousand Oaks, CA: Sage.

Cunningsworth, A. (1995). Choosing your Coursebook. Oxford: Heinemann.

Dat, B. (2003) Materials for developing speaking skills. In B. Tomlinson (Ed.), Developing Materials for Language Teaching, (pp.375-393). London: Continuum Press.

Dörnyei, Z. (2007). Research methods in Applied Linguistics: Quantitative, Qualitative, and Mixed Methodologies. Oxford: Oxford University Press.

El-Mostafa, A. (1988). An evaluation of the TEFL textbook (PETRA) for the first preparatory class in Jordan. Unpublished master's thesis, Yarmouk University, Irbid, Jordan.

Graves, K. (1996). Teachers as course developers. In K. Graves (Ed.), Teachers as Course Developers, (pp.1-11). Cambridge: Cambridge University Press.

Graves, K. (2000). Designing Language Course: A Guide for Teachers. Boston: Heinle \& Heinle.

Masuhara, H. and Tomlinson, B. (2008). Materials for general English. In B. Tomlinson (Ed.), English Language Learning Materials: A Critical Review, (pp.17-37). London: Continuum.

McDonough, J. and Shaw, C. (2003). Materials and Methods in ELT: A Teacher's guide (2nd ed.). Oxford: Blackwell. McGrath, I. (2002). Materials Evaluation and Design for Language Teaching. Edinburgh: Edinburgh University Press.

Mckay, S. (2002). Teaching English as an International Language: Rethinking Goals and Approaches. Oxford: Oxford University Press.

Mukundan, J. (2009). ESL Textbook Evaluation: A Composite Framework. Germany: Lambert Academic Publishing $\mathrm{AG}$ and Co. KG. 
Oxford, R. L. (2001). Language learning styles and strategies. In M. Celce-Murcia (Ed), Teaching English as Second or Foreign Language (3rd ed., pp.359-366). Boston: Heinle \& Heinle.

Richards, J. (2001). Curriculum Development in Language Education. Cambridge: Cambridge University Press.

Saleh, N. (1990). An evaluation of the TEFL textbook (PETRA) for the second preparatory class in Jordan. Unpublished master's thesis, Yarmouk University, Irbid, Jordan.

Saraceni, C. (2003). Adapting courses: A critical view. In B. Tomlinson (Ed), Materials Development for Language Teaching, (pp.72-85). London: Continuum Press.

Shatnawi, M. (2005). The cultural dimension in TEFL: a case study of the 'Cutting Edge' series. Unpublished doctoral dissertation, Amman Arab University for Graduate Studies, Amman, Jordan.

Timmis, I. (2004). Materials design principled compromise and compromised principles? Folio, 9(1), 11-14.

Tomlinson, B. (Ed.). (1998). Materials Development in Language Teaching. Cambridge: Cambridge University Press.

Tomlinson, B. (1999). Developing criteria for evaluating L2 materials. IATEFL Issues, 147, 10-13.

Tomlinson, B. (2001). Materials development. In R. Carter \& D. Nunan (Eds.), The Cambridge Guide to Teaching English to Speakers of Other Languages, (pp.66-71). Cambridge: Cambridge University Press.

Tomlinson, B. (Ed.). (2003a). Materials Development for Language Teaching. London: Continuum Press.

Tomlinson, B. (2003b). Materials evaluation. In B. Tomlinson (Ed.), Developing Materials for Language Teaching, (pp.15-36). London: Continuum.

Tomlinson, B. \& Masuhara, H. (2004). Developing Language Course Materials. Singapore: RELC Portfolio Series. Ur, P. (1996). A Course in Language Teaching: Practice and Theory. Cambridge: Cambridge University Press.

\section{Appendices}

Appendix A

\section{Teachers' Interview Guide}

1- Do you think that the current materials and their objectives correspond with your learners' needs? Why (not)?

2-What changes would you like to see?

3- What do you like and/or dislike about the reading texts?

4- How useful and effective do you think the teacher's book is? For example:

a- Does it provide you with adequate guidance in how to teach the materials?

b- Does it include useful information about the lessons, lexical items, exams, etc?

c- Does it help you to develop your language skills?

5- What in your opinion are the most positive characteristics of the English materials "Jordan Opportunities"?

6- What in your opinion are the most negative characteristics of the English materials "Jordan Opportunities"?

7- SUGGESTIONS to improve the materials "Jordan Opportunities":

Any Other Comments: 
Appendix B

Learners' Interview Guide

1- What in your opinion are the most useful activities in the current English language materials "Jordan Opportunities"?

2- What in your opinion are the least useful activities in the English materials "Jordan Opportunities"?

3- What do you like and/or dislike about the reading texts?

4- What in your opinion are the strong points in the English language materials "Jordan Opportunities"?

5- What in your opinion are the weak points in the English language materials "Jordan Opportunities"?

6- SUGGESTIONS to improve the materials "Jordan Opportunities":

Any Other Comments: 